\title{
THE STUDY OF MOBILE LASER SCANNING DATA ADJUSTMENT RESULTS FOR LARGE SCALE TOPOGRAPHIC MAPPING
}

\author{
M.A. Altyntsev ${ }^{1, *}$, Karkokli Hameed Majeed Saber ${ }^{2}$ \\ ${ }^{1}$ Dep. of Engineering Geodesy and Mine Surveying, Siberian State University of Geosystems and Technologies, Novosibirsk, \\ Russian Federation - mnbcv@mail.ru \\ ${ }^{2}$ Dep. of Engineering Geodesy and Mine Surveying, Siberian State University of Geosystems and Technologies, Novosibirsk, \\ Russian Federation - enghamid72@yahoo.com
}

\section{Commission II, WG II/3}

KEY WORDS: Mobile laser scanning, Large scale topographic mapping, Adjustment, Accuracy estimation, Control points, GNSS signal

\begin{abstract}
:
Mobile laser scanning (MLS) data are widely used for solving various tasks. To be sure that these data are appropriate for a specific task it is necessary to adjust data with a certain accuracy. Large scale topographic mapping is one from the tasks often solved by MLS data. Necessary accuracy of creating topographic plans is determined with a requirements document. Topographic plans are always created in a certain coordinate system. For this reason, MLS data should be previously transformed in the required one. For transformation control points measured with other more accurate methods should be applied. The quantity of necessary control points depends on a surveying area. For urban areas a lot of control points are required due to bad quality of GNSS signal. Much research has been conducted for these areas. For areas with open view of the sky it is required significantly fewer control points. Moreover, there are not so many vertical objects in areas with open view of the sky. Large errors can take place in the result of automatic adjustment of point cloud's multi-passes. The results of both relative and absolute MLS data adjustment are given for the area with a good GNSS signal. The paper presents the results of accuracy estimation with different quantity of control points. The main goal of the paper is to determine the minimum number of control points for MLS data to be appropriate for creating topographic plans at a scale of 1:500 with a contour interval of $0.25 \mathrm{~m}$.
\end{abstract}

\section{INTRODUCTION}

Mobile laser scanning has become a popular method of surveying all over the world. This method allows gathering data for very short period of time with high accuracy and density. The result of MLS is a point cloud where each point has threedimensional coordinates. The are many advantages of applying MLS. This is the cost-efficient method that provides the data for generating 3D models and topographic plans, detecting road cracks, determining road parameters such as width and gradient, constructing its cross-sections (Guan et al., 2014).

MLS systems are being developed for collecting point clouds from a street view. MLS systems are usually equipped with 2 laser scanners, digital cameras, 2 GNSS antennas, an inertial measurement unit (IMU), a distance measurement instrument (DMI), a control unit and an operating computer. The control unit and the operating computer are placed in a vehicle. The other blocks are mounted on a platform located on the vehicle roof (Wang et al., 2019).

A lot of companies manufacture MLS systems. As a rule, these are large companies such as Trimble, Topcon, Optech, Leica and Riegl (Wang et al., 2019). Each of these companies has its own software for MLS data processing. The main task of this software is calibration of MLS systems and data adjustment. During calibration relative orientation parameters are defined between 2 laser scanners. Data adjustment requires multiple scans of the same scene and ground control points (GCP).
Multiple scans are used for relative data adjustment while GCPs are necessary for absolute one (Hussnain et al., 2018).

Rapid development of MLS technology contributes to introducing new algorithms and techniques of MLS system calibration and data adjustment. Modern software from mentioned companies is capable to carry out these processes almost fully automatically in most cases. The software corrects a point cloud and a trajectory with automatic registration of multiple passes, similar to the technique reported by Ding et al. (2007), Levinson et al. (2007) and Zhao (2011). Algorithms and techniques are being also developed by not large companies and scientific institutes. Some of them construct low-cost and compact MLS systems which demand developing additional methods of data adjustment (Julge et al., 2017).

Final accuracy of MLS data adjustment depends on such factors as technical characteristics of MLS system, the quality of GNSS measurements, base-line length between MLS system and a reference station, the number of reference stations and GCPs.

The quality of GNSS measurements is influenced with the scanned area type. According to technical characteristics of most MLS systems absolute data accuracy is $5 \mathrm{~cm}$ both in XY and Z coordinates for good quality of GNSS measurements. To receive good GNSS signals it is necessary to provide open view of the sky. It is not always possible when scanning some areas. Buildings, tunnels, foliage, various constructions interfere GNSS signals. GNSS antenna defines linear exterior orientation

\footnotetext{
* Corresponding author
} 
parameters. Angular ones are calculated with IMU which also allows compensating GNSS signal short-term loss in such areas (Altyntsev, Popov, 2014).

GCPs are used to reach absolute accuracy of $5 \mathrm{~cm}$ and better when GNSS signals are poor or they are lost. Schaer and Vallet (2016) demonstrated that GNSS outages longer than 30-60 seconds may lead to a rapid decrease in absolute positioning accuracy when driving at $40-50 \mathrm{~km} / \mathrm{h}$. In case the GNSS signals are lost the positional drift reaches its maximum in the middle of the section. They offered to use GCPs every $400 \mathrm{~m}$ to reach a desired accuracy better than $5 \mathrm{~cm}$. To correct MLS trajectory the manual identification of GCPs in the point cloud is required.

For adjustment of MLS point clouds and trajectories aerial images can be used. Gao et al. (2015) proposed a framework for adjusting MLS point cloud through UAV images automatically. The main essence of the framework as follows: road marking extraction from MLS point cloud based on intensity values, interpolation of point cloud intensity data, aerial triangulation of UAV images, pairwise registration of these images and point cloud based on feature point extraction with Harris corner keypoint detection, point matching using a local edge-based template, point cloud adjustment. The accuracy of $6-10 \mathrm{~cm}$ was reached. However, they performed the adjustment of the point cloud and did not estimate the trajectory accuracy.

Hussnain et al. (2018) developed an automatic method of both point cloud and trajectory adjustment in GNSS denied areas by extracting corresponding 3D tie points between aerial images and an MLS point cloud. Aerial imagery is an external source of GCPs for computing reliable exterior orientation parameters (Hussnain et al., 2019). Using described method they have adjusted the MLS trajectory with accuracy of 9-14 cm.

Javanmardi et al (2017) used multiple reference data sets including aerial imagery to adjust MLS point cloud. They developed a sliding window algorithm for matching geometric features between images and point cloud. As the features a road marking was also proposed to apply. Hu et al. (2019) offered to apply pole-like infrastructures in addition to a road marking for trajectory adjustment.

Thus, the great number of algorithms and techniques have been developing for poor quality of GNSS measurements in dense urban areas where a lot of GCPs are needed for improving accuracy of adjusted MLS data. Measuring of GCP coordinates with terrestrial classical methods like a tacheometric survey and a survey using GNSS receivers is very time-consuming. In this case application of aerial imagery can reduce the average distance between two control points till 100-200 m instead of using hundred control points along the road collected under field conditions [Gao et al., 2015].

It may be unnecessary to apply GCPs when scanning outside urban areas in places where GNSS signals are good. Only some check points can be applied to be sure of required accuracy. When this occurs application of aerial images becomes inefficiently. Classical method will be the best choice. In this case we should take into account recommendations about maximum base-line length to a reference station. The positional accuracy gets worse with increasing distance to it. Scherzinger, and Hutton (2020), Hutton and Roy (2020) described these recommendations for data processed in POSPac MMS software developed by Applanix company. This software helps to adjust MLS trajectories. Applanix company produces equipment for many MLS systems. The base-line length between the roving receiver installed in MLS system and the reference station have to be limited to no more than $30 \mathrm{~km}$. If base-line length exceeds this distance a network of reference stations should be used. The network must include from 4 to 50 reference stations for processing in POSPac MMS. The maximum distance from the rover to the nearest reference station in the network is no more than about $70 \mathrm{~km}$. To reduce errors the scanning should be carried out inside a polygon defined by reference stations.

The final decision about necessity of applying GCPs in territories with good GNSS signals or about a choice of average distance between two GCP has to depend on the final production obtained on the basis of an MLS point cloud.

MLS are often applied for mapping of linear long-distance territories. Topographic plans are created using an MLS point cloud. Horizontal and vertical positional accuracy of topographic plan's objects must not exceed values given in SP 47.13330.2016 «Engineering survey for construction. Basic principles» (2016). To meet the requirements of this manual allowable errors are calculated for the certain scale of topographic plan and contour interval.

In the paper the method of MLS is analyzed for the goal of mapping. Next issues are discussed: creating geodetic control network for MLS, the scheme of MLS for long-distance areas, adjustment of MLS data including the analysis of accuracy estimation with different numbers of control points. As measuring of control point coordinates with terrestrial classical methods is very time-consuming, it is necessary to determine minimum allowed number of control points for MLS data to match the accuracy of large scale topographic mapping. It should be also determined the maximum base-line length between the roving receiver of an MLS system and the reference station for this goal. The study is carried out on the basis of data gathered for roads within oil and gas deposits.

\section{MAPPING OF OIL AND GAS DEPOSITS}

Oil and gas deposit areas are represented by complicated industrial infrastructure such as pipelines, buildings, tanks, power lines. A roadway network is constructed among different oil and gas areas. For mapping of these areas and roads different methods can be used. MLS is preferable for long roads.

In 2017 mobile laser scanning war carried out for a road between Talakan oil and gas deposit and Vitim. Vitim is an urban locality in Russia. The goal of MLS was creating a topographic plan at a scale of 1:500 with a contour interval of $0.25 \mathrm{~m}$. The length of the road was $160 \mathrm{~km}$.

The first stage of field works was creating geodetic control network for MLS. It was done with Trimble R8 satellite receivers. The scheme of creating geodetic control network is presented in Figure 1. There were used 6 points of the state geodetic network for measuring coordinates of 27 geodetic control network points. 4 of 27 points were applied for placing reference stations while MLS. 24 of 27 points were needed for an employer to carry out additional works connected with road maintenance and these points were not used for MLS. 


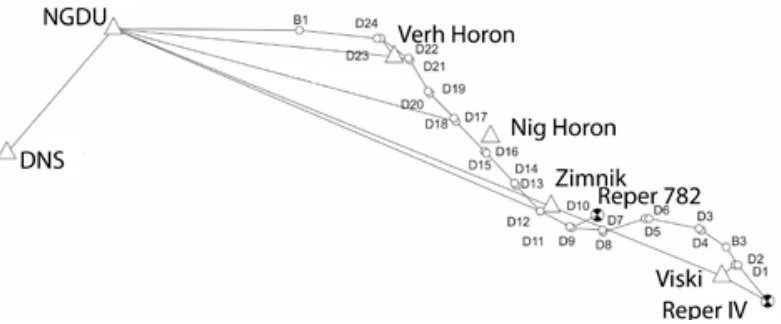

Figure 1. The scheme of creating geodetic control network

The system Riegl VMX-250 was chosen for scanning of the road. In this system IMU by Applanix company is applied and trajectories are processed in POSPac MMS software. According to the requirements described by Hutton and Roy (2020) the MLS for this road has to be carried out when at least 4 reference stations are simultaneously operated. In this case MLS of 160 $\mathrm{km}$ could be done in 1 day. The absolute measuring accuracy for ground point coordinates should have been within $5 \mathrm{~cm}$ owing to stated specifications of the system.

However, it was decided to apply only 1 reference station while scanning because of safety reasons. The territory is occupied by a large number of wild animals. While MLS each reference station must operate continuously. To meet this requirement a surveyor turns on a GNSS receiver on a reference station before MLS starts and turns off it after MLS finishers. The more reference stations are used the more surveyors are needed. Every surveyor must be protected.

As it was discussed earlier in case of applying only 1 reference station the MLS system shall not be more than $30 \mathrm{~km}$ away from it. To provide better accuracy it was decided not to move more than $15 \mathrm{~km}$ away from the station. The territory of surveying was divided in 7 parts. Laser scanning was carried out along each part of the territory both in forward and backward directions with the vehicle's average speed of 40 $\mathrm{km} / \mathrm{h}$. In Figure 2 the scheme of MLS is shown. Geodetic control network points with numbers of B1, B2, B3 and D20 were used for placing reference stations. NGDU and DNS are continuously operating reference stations (CORS) that were used while scanning the western part of the territory. Certain color of the vehicle's trajectory demonstrates the reference station number used for scanning. The trajectory near NGDU station was divided in 2 parts because MLS of this territory was conducted for 2 days.

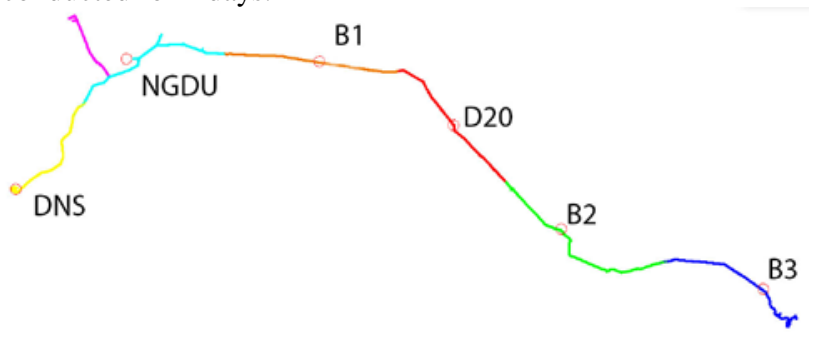

Figure 2. The scheme of MLS

At first MLS was conducted for territories within operating the CORS. Then a GNSS receiver mounted on the reference station with number of B1 operated during MLS of the corresponding trajectory part. After that the receiver was moved to the next reference station for scanning the next part of the road. The territory around the reference station with the number of B3 was scanned in the last turn.

\section{RELATIVE ADJUSTMENT OF MLS DATA}

Because of applying only one GNSS receiver each part of the trajectory was adjusted in the POSPac MMS software separately. Adjusted trajectories and raw point cloud data were imported to Riprocess software where coordinates of laser points had been separately calculated for each part of the adjusted trajectory. Automatic adjustment of point cloud's multi-passes is carried out in Riprocess software accordingly to an algorithm described by Rieger et al. (2010). The algorithm works well in areas where there are a lot of vertical objects such as walls of buildings. In urban areas horizontal positional errors aim for least values even within one part of the trajectory. The large errors in horizontal position can occur in areas without these objects. Vertical positional errors usually aim for least errors in any type of areas after relative adjustment within one part of the trajectory.

Thus, 7 parts of MLS data were separately and automatically adjusted. The adjacent trajectory parts overlapped slightly. To check errors between the adjacent trajectory parts check points were used. Horizontal and vertical positional errors were estimated independently of each other. To estimate vertical positional errors, check points were automatically found on the road surface in the overlapping areas. To estimate horizontal positional errors, check points were manually placed on road signs. Manual placement of check point was needed because of impossibility for the algorithm to find horizontal positional points. The road Talakan - Vitim was surrounded almost throughout by high vegetation. There were almost no walls within the surveying territory. In Figure 3 the example of a manually placed check point is demonstrated.

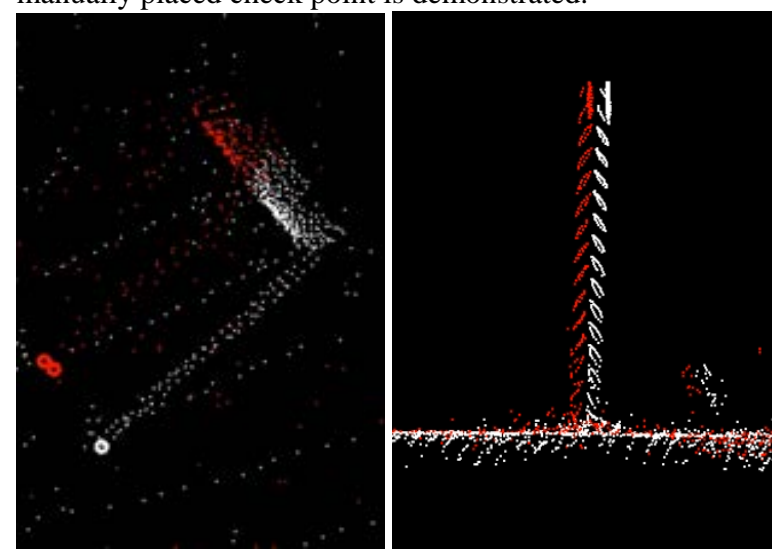

Figure 3. Horizontal positional error between point cloud's multi-passes

The results of the relative accuracy estimation using the check points are given in Table 1 . Totally, 56 horizontal check points and 232 vertical ones were used. It is seen that vertical positional maximum error is rather larger in overlapping areas and exceeds stated specifications of the system in several times.

\begin{tabular}{|c|c|c|c|}
\hline & $\mathrm{X}, \mathrm{m}$ & $\mathrm{Y}, \mathrm{m}$ & $\mathrm{Z}, \mathrm{m}$ \\
\hline Mean error & 0.036 & 0.046 & 0.023 \\
\hline RMS error & 0.040 & 0.052 & 0.048 \\
\hline Maximum error & 0.068 & 0.084 & 0.297 \\
\hline
\end{tabular}

Table 1. Relative accuracy estimation of MLS data using check points

For MLS data adjustment of the whole territory including overlapping areas half of check points were used as control ones. The remaining check points were applied for accuracy estimation after adjustment. Table 2 illustrates the results of 
relative accuracy estimation of MLS data adjustment using control points, whereas using check points - in Table 3. The MLS data were adjusted in a UTM projection.

\begin{tabular}{|c|c|c|c|}
\hline & $\mathrm{X}, \mathrm{m}$ & $\mathrm{Y}, \mathrm{m}$ & $\mathrm{Z}, \mathrm{m}$ \\
\hline Mean error & 0.009 & 0.004 & 0.003 \\
\hline RMS error & 0.012 & 0.007 & 0.010 \\
\hline Maximum error & 0.033 & 0.025 & 0.046 \\
\hline
\end{tabular}

Table 2. Relative accuracy estimation of MLS data adjustment using control points

\begin{tabular}{|c|c|c|c|}
\hline & $\mathrm{X}, \mathrm{m}$ & $\mathrm{Y}, \mathrm{m}$ & $\mathrm{Z}, \mathrm{m}$ \\
\hline Mean error & 0.013 & 0.011 & 0.007 \\
\hline RMS error & 0.020 & 0.013 & 0.016 \\
\hline Maximum error & 0.037 & 0.036 & 0.055 \\
\hline
\end{tabular}

Table 3. Relative accuracy estimation of MLS data adjustment using check points

\section{ABSOLUTE ADJUSTMENT OF MLS DATA}

Topographic plan at a scale of 1:500 must have been created in a local coordinate system required for the employer. To transform MLS data from UTM coordinates to local ones 8 points of the geodetic network showed in Figure 1 were used: B1, B2, B3, D20, REPER 782, DNS, NGDU and Viski. These points were evenly distributed within the surveying area. Local coordinates of these points were known and UTM coordinates were measured with GNSS receivers. At first, there were calculated transformation parameters using 3D affine transformation with 9 parameters which is defined by equations (Wu et al., 2013):

$$
\left[\begin{array}{c}
X_{A} \\
Y_{A} \\
Z_{A}
\end{array}\right]=\left[\begin{array}{c}
x_{0} \\
y_{0} \\
z_{0}
\end{array}\right]+S\left(\lambda_{1}\right) S\left(\lambda_{2}\right) S\left(\lambda_{3}\right) \times R(\omega) R(\varphi) R(\kappa)\left[\begin{array}{c}
X_{B} \\
Y_{B} \\
Z_{B}
\end{array}\right](1)
$$

where $X_{A}, Y_{A}, Z_{A}=$ local coordinates

$X_{B}, Y_{B}, Z_{B}=$ UTM coordinates

$x_{0}, y_{0}, z_{0}=$ the translation parameters of origin of the two coordinate systems systems

$\lambda_{1}, \lambda_{2}, \lambda_{3}=$ the scale parameter of the two coordinate systems

$\omega, \varphi, \kappa=$ the rotation angles of the two coordinate

Table 4 demonstrates the accuracy of transforming 8 geodetic network points from UTM coordinates to local ones using calculated 3D affine transformation parameters. The calculated 3D affine transformation parameters were applied for transforming MLS data from UTM projection to the local coordinate system.

\begin{tabular}{|c|c|c|c|}
\hline & $\mathrm{X}, \mathrm{m}$ & $\mathrm{Y}, \mathrm{m}$ & $\mathrm{Z}, \mathrm{m}$ \\
\hline Mean error & 0.001 & 0.001 & 0.030 \\
\hline RMS error & 0.001 & 0.001 & 0.034 \\
\hline Maximum error & 0.001 & 0.001 & 0.06 \\
\hline
\end{tabular}

Table 4. Accuracy estimation of transforming geodetic network point coordinates

To estimate accuracy of transformed MLS data it is necessary to use control and check points placed within the point cloud which coordinates are measured with more accurate land surveying equipment such as GNSS receivers and total stations.
The final absolute accuracy of MLS data adjustment using control and check point determines the usability of these data for creating topographic plans at a certain scale and a contour interval. According to (Engineering survey for construction. Basic principles., 2016) average errors for horizontal position of objects and terrain contours with clear recognizable edges should not exceed $0.5 \mathrm{~mm}$ at plotting plan scale for not built-up areas relative to the nearest points of a geodetic control network. Average errors for their vertical position should not exceed $1 / 4$ of the accepted contour interval for flat terrain (surface slope up to $2^{\circ}$ ) and $1 / 3$ - for surface slope greater than $2^{\circ}$. Maximum errors shall not exceed twice values of mean errors in both horizontal and vertical positions. Errors exceeding the maximum allowed values should be eliminated. At the same time the number of them shall not exceed $10 \%$ of the total number of check measurements.

The average slope of the surveyed road was greater than $2^{\circ}$. For the scale of 1:500 horizontal positional accuracy must not exceed $25 \mathrm{~cm}$ for mean values and $50 \mathrm{~cm}$ for maximum ones. For the contour interval of $25 \mathrm{~cm}$ vertical one must not exceed $8.3 \mathrm{~cm}$ for mean values and $16.6 \mathrm{~cm}$ for maximum ones.

Based on calculated tolerances and the fact that the quality of GNSS measurements for the road Talakan - Vitim was well, the quantity of required ground control points had to be not so large comparing to urban areas. It was decided to place ground points along the road every $1 \mathrm{~km}$. In Figure 4 the example of placing ground points is shown. They were located on the road surface edge in opposite of distance marks. It is the center of yellow circle. A distance mark is shown in the form of red symbol. Parallel cyan lines display road edges. GNSS receivers were used for measuring coordinates of ground points. The maximum error of measuring ground point coordinates did not exceed 3 $\mathrm{cm}$ relatively to geodetic control network in horizontal and vertical position.

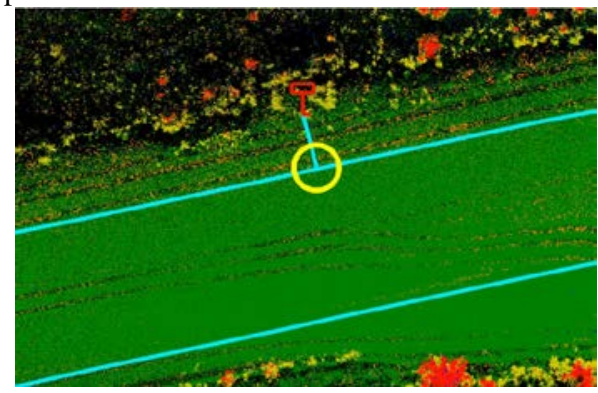

Figure 4 . The example of placing ground points

Ground point locations were identified in the point cloud. At first ground points were used as check ones. There were calculated distances between ground points measured in the point cloud and those measured with GNSS receivers. The results of calculations are given in Table 5 .

\begin{tabular}{|c|c|c|c|}
\hline & $\mathrm{X}, \mathrm{m}$ & $\mathrm{Y}, \mathrm{m}$ & $\mathrm{Z}, \mathrm{m}$ \\
\hline Mean error & 0.009 & 0.010 & 0.047 \\
\hline RMS error & 0.016 & 0.022 & 0.041 \\
\hline Maximum error & 0.116 & 0.228 & 0.218 \\
\hline
\end{tabular}

Table 5. Absolute accuracy estimation of MLS data adjustment using check points every $1 \mathrm{~km}$ and without control points

It is seen from the Table 5 that horizontal positional accuracy is appropriate for creating topographic plans at a scale of 1:500, whereas vertical one is too large. The value of maximum error exceeds the calculated tolerance. It means that application of control points for adjustment is necessary. A trajectory part with 
the maximum error is seen from Figure 5 which demonstrates error distribution. It is the place in the middle of the trajectory part between control network points with numbers of B2 and B3. A direct distance between these network points is $29 \mathrm{~km}$. The trajectory part with errors exceeding the calculated tolerance of $16.6 \mathrm{~cm}$ for vertical measurements is located at a distance of $14.5 \mathrm{~km}$ from B2 and $13.4 \mathrm{~km}$ from B3. It can be assumed that placing 1 control point in the middle of this trajectory part would be sufficient to meet the tolerance. Error distribution for other trajectory parts does not exceed the tolerance. The length of the other trajectory parts is less than the one between B2 and B3. It is $23.5 \mathrm{~km}$ between DNS and NGDU, 26.7 km between NGDU and B1, $20.5 \mathrm{~km}$ between B1 and D20, $20.5 \mathrm{~km}$ between D20 and B2.

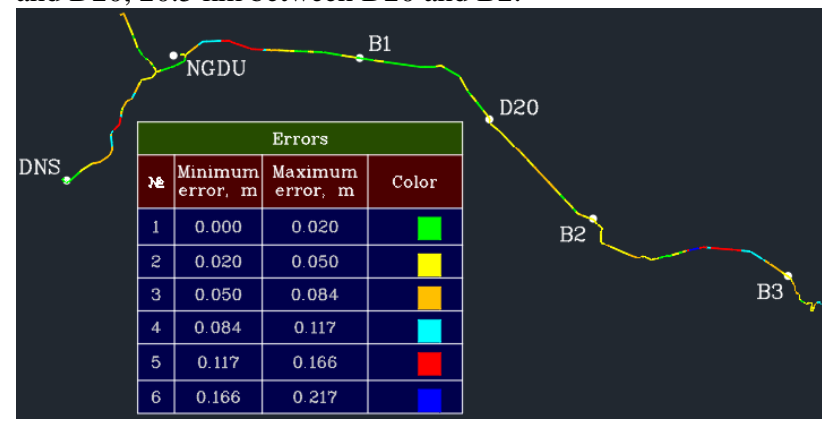

Figure 5. Error distribution for MLS data using check points every $1 \mathrm{~km}$ and without control points

To obtain adjusted point cloud with high accuracy and within the tolerance it was decided to study how point cloud adjustment results depend on the number of control points and distances between them. In case of applying all ground points as control ones, errors from the Table 5 equal to zero. It is due to the algorithm used for transformation of the MLS data. The algorithm is optimized for local accuracy. It means that this algorithm transforms the source point cloud exactly to target control points. Transformation is carried out with specifying difference values in every control point for northing, easting and elevation.

Without check points absolute accuracy estimation does not seem complete. For this reason, ground points were divided equally into control and check ones. In other words, both check and control points were used every $2 \mathrm{~km}$. Absolute accuracy estimation of MLS data adjustment using control and check points every $2 \mathrm{~km}$ is given in Table 6 .

\begin{tabular}{|c|c|c|c|}
\hline & $\mathrm{X}, \mathrm{m}$ & $\mathrm{Y}, \mathrm{m}$ & $\mathrm{Z}, \mathrm{m}$ \\
\hline Mean error & 0.014 & 0.017 & 0.020 \\
\hline RMS error & 0.016 & 0.016 & 0.022 \\
\hline Maximum error & 0.085 & 0.064 & 0.110 \\
\hline
\end{tabular}

Table 6 . Absolute accuracy estimation of MLS data adjustment using check points every $2 \mathrm{~km}$ and control points every $2 \mathrm{~km}$

Maximum error of vertical position was decreased in 2 times and started to be within the tolerance. This means that application of control points every $2 \mathrm{~km}$ is enough for scanning this road. Figure 6 demonstrates error distribution for MLS data adjustment using check points every $2 \mathrm{~km}$ and control points every $2 \mathrm{~km}$. The trajectory part with the maximum error is located between control network points with numbers of B2 and B3 as for MLS data adjusted without control points.

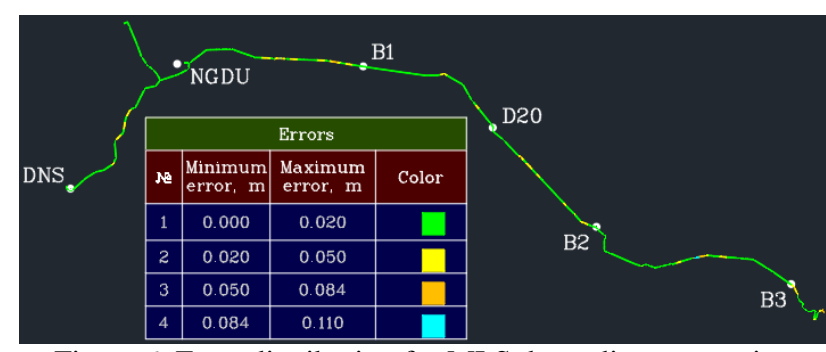

Figure 6. Error distribution for MLS data adjustment using check points every $2 \mathrm{~km}$ and control points every $2 \mathrm{~km}$

Next, it was decided to take every fourth ground point as control one, the others - as check ones. The results of accuracy estimation with this number of control and check points are given in Table 7. Figure 7 demonstrates error distribution for MLS data adjustment using check points every $1 \mathrm{~km}$ and control points every $4 \mathrm{~km}$. Comparing to the previous results the values of errors were not dramatically changed.

\begin{tabular}{|c|c|c|c|}
\hline & $\mathrm{X}, \mathrm{m}$ & $\mathrm{Y}, \mathrm{m}$ & $\mathrm{Z}, \mathrm{m}$ \\
\hline Mean error & 0.014 & 0.013 & 0.020 \\
\hline RMS error & 0.020 & 0.017 & 0.023 \\
\hline Maximum error & 0.123 & 0.098 & 0.117 \\
\hline
\end{tabular}

Table 7. Absolute accuracy estimation of MLS data adjustment using check points every $1 \mathrm{~km}$ and control points every $4 \mathrm{~km}$

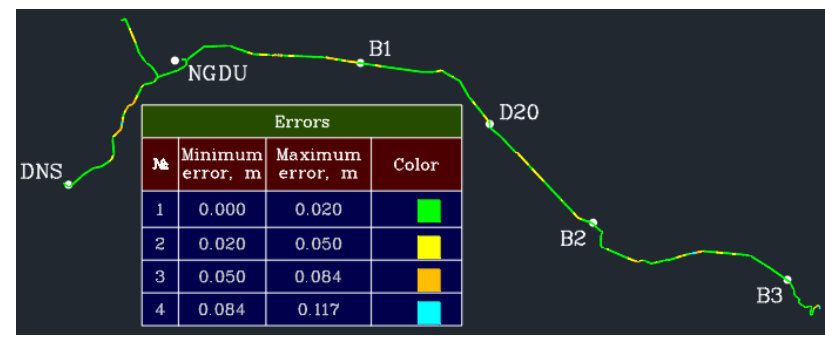

Figure 7. Error distribution for MLS data adjustment using check points every $1 \mathrm{~km}$ and control points every $4 \mathrm{~km}$

At the end every eighth ground point was taken as control one, the others - as check ones. Table 8 shows accuracy estimation results of MLS data adjustment with such number of check points and Figure 8 - error distribution.

\begin{tabular}{|c|c|c|c|}
\hline & $\mathrm{X}, \mathrm{m}$ & $\mathrm{Y}, \mathrm{m}$ & $\mathrm{Z}, \mathrm{m}$ \\
\hline Mean error & 0.018 & 0.016 & 0.028 \\
\hline RMS error & 0.028 & 0.020 & 0.033 \\
\hline Maximum error & 0.170 & 0.110 & 0.170 \\
\hline
\end{tabular}

Table 8. Absolute accuracy estimation of MLS data adjustment using check points every $1 \mathrm{~km}$ and control points every $8 \mathrm{~km}$

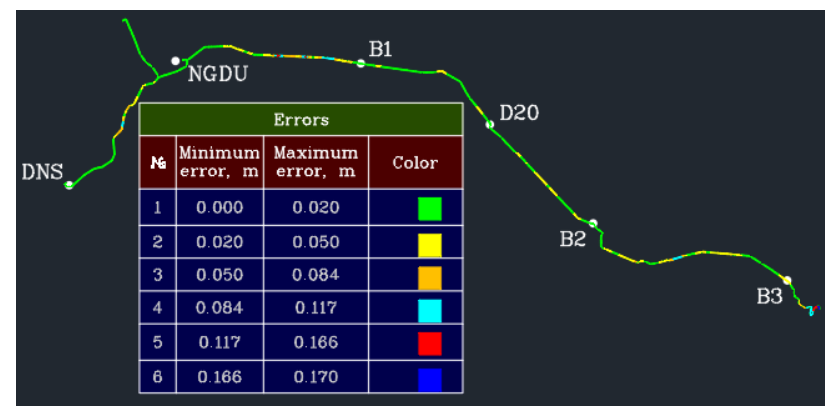

Figure 8. Error distribution for MLS data adjustment using check points every $1 \mathrm{~km}$ and control points every $8 \mathrm{~km}$

Table 8 demonstrates that the maximum error exceeds the calculated tolerance and Figure 8 shows the part of the 
trajectory with this error. The place with the maximum error is located at the start of the road near the control network point with the number of B3. The accuracy of MLS data adjustment became worse in this trajectory part. The comparison of the trajectory obtained without adjustment using control points and the one obtained with control points every $8 \mathrm{~km}$ is shown in Figure 9. It can be explained by the fact that a control point with the number CP1 is located rather far from the start of the road (4 $\mathrm{km}$ in direct direction).

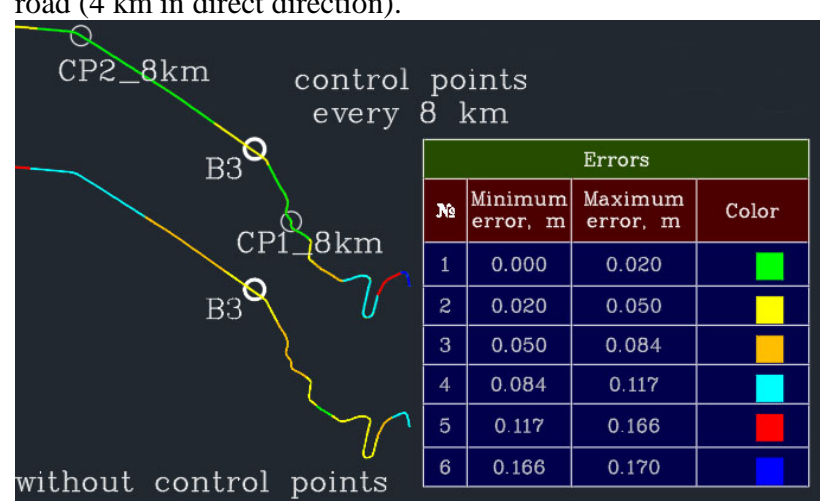

Figure 9. The comparison of the trajectoriy adjusted with control points every $8 \mathrm{~km}$ and the trajectory without adjustment using control points

To eliminate large errors at the start of the road it should be have used a control point with the number of CP0 showed in Figure 10 instead of the one with the number of CP1. The ground point $\mathrm{CP} 0$ was used as control one when using control points every $2 \mathrm{~km}$.

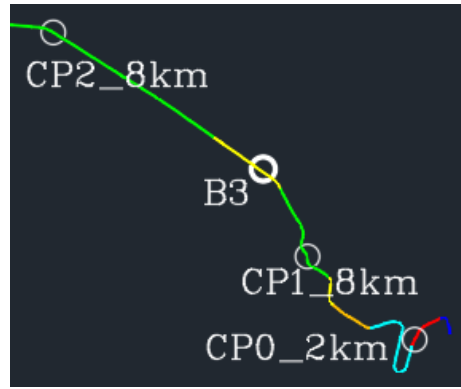

Figure 10. The choice of placing control points

No further increase in distance between control points is required because of limited distance between reference station. Thus, it may be concluded that for the goal of large scale topographic mapping application of control points every $8 \mathrm{~km}$ is enough for scanning a road outside urban areas with Riegl VMX-250 system when a GNSS signal is good. In this case it must be provided measuring control points at the very edges of trajectories.

Application of fewer amount of control points allows to speed up the process of field surveying works. If a distance between nearest reference stations does not exceed $26.7 \mathrm{~km}$, as the distance between control network points NGDU and B1, and GNSS conditions are excellent control points may not be required. In this case half of the distance should be scanned when launching one reference station, and the second half when launching a nearby station.

\section{CONCLUSION}

The results of relative accuracy estimation of data adjusted with automatic algorithms shows that if around surveying area there are almost no vertical walls horizontal positional errors will be much greater than for urban areas. Additional manual adjustment is needed. For roads distance marks can be used as horizontal control points.

The results of absolute accuracy estimation demonstrate that not so many control points are required to adjust MLS data if the goal of laser scanning is large scale topographic mapping of long-distance areas with open view of the sky. For the Riegl VMX-250 system it is enough to measure coordinates of control points every $8 \mathrm{~km}$. Control points should be placed on the road surface. They also must be located at the very beginning and the end of a trajectory.

In spite of recommendation of Scherzinger and Hutton (2020), Hutton and Roy (2020), the results of the study also showed that for creating topographic plans at a scale of 1:500 with a contour interval of $0.25 \mathrm{~cm}$ it is not recommended to increase the base-line length between the roving receiver installed in MLS system and the reference station by more than $13 \mathrm{~km}$ to have the opportunity not to use control points on the road. In the contrary case ground-based surveying methods should be used for absolute adjustment of MLS data. Aerial methods are not efficient to use as a source of control points even if the GNSS signal is continuous and has good quality.

\section{REFERENCES}

Altyntsev, M. A., Popov R.A., 2014. The Analysis of GPS Signal Short-term Loss Influence on the Accuracy of Mobile Laser Scanning Data. XXV FIG Congress, 16-21 June 2014, Malaysia, Kuala Lumpur.

Ding, W., Wang, J., Rizos, C., Kinlyside, D., 2007. Improving adaptive Kalman estimation in GPS/INS integration. Journal of Navigation, 60(03), 517-529. doi.org/10.1017/S0373463307004316

Gao, Y., Huang, X., Zhang, F., Fu, Z., Yang, C., 2015. Automatic geo-referencing mobile laser scanning data to UAV images. ISPRS - International Archives of the Photogrammetry, Remote Sensing and Spatial Information Sciences, XL-1/W4, 41-46. doi.org/10.5194/isprsarchives-XL-1-W4-41-2015.

Guan, H., Li, J., Yu, Y., Wang, C., Chapman, M., Yang, B., 2014. Using mobile laser scanning data for automated extraction of road markings. ISPRS Journal of Photogrammetry and Remote Sensing. 87 (2014), 93-107.

Hu., H., Sons., M., Stiller. C., 2019. Accurate Global Trajectory Alignment using Poles and Road Markings. arXiv:1903.10205v1.

Hussnain, Z., Oude Elbernk, S., Vosselman., G., 2018. An automatic procedure for mobile laser scanning platform 6dof trajectory adjustment. ISPRS - International Archives of the Photogrammetry, Remote Sensing and Spatial Information Sciences, XLII-1, 203-209. doi.org/10.5194/isprs-archivesXLII-1-203-2018.

Hussnain, Z., Oude Elbernk, S., Vosselman., G., 2019. Automatic extraction of accurate 3D tie points for trajectory adjustment of mobile laser scanners using aerial imagery. ISPRS Journal of Photogrammetry and Remote Sensing, 154, 41-58. doi.org/10.1016/j.isprsjprs.2019.05.010. 
Javanmardi, M., Javanmardi, E., Gu, Y., Kamijo, S., 2017. Automatic calibration of 3D mobile laser scanning using aerial surveillance data for precise urban mapping. IEEE Intelligent Vehicles Symposium (IV), Los Angeles, CA, 1182-1188. doi.org/10.1016/j.isprsjprs.2019.05.010.

Julge, K., Vajakas, T., Ellmann, A., 2017. Performance analysis of a compact and low-cost mapping-grade mobile laser scanning system. Journal of Applied Remote Sensing, 11(4), 044003.

Levinson, J., Montemerlo, M., Thrun, S., 2007. Map-Based Precision Vehicle Localization in Urban Environments. Robotics: Science and Systems III. doi.org/10.15607/RSS.2007.III.016

Rieger, P., Studnicka, N., Pfennigbauer, M., 2010. Boresight alignment method for mobile laser scanning systems. Journal of Applied Geodesy, 4(1), 13-21. doi.org/10.1515/JAG.2010.002.

Schaer, P., Vallet, J., 2016. Trajectory adjustment of mobile laser scan data in GPS denied environments. ISPRS International Archives of the Photogrammetry, Remote Sensing and Spatial Information Sciences, XL-3/W4, 61-64. doi.org/10.5194/isprsarchives-XL-3-W4-61-2016.

Wang., Y., Chen., Q., Zhu., Q., Liu., L., Li., C., Zheng., D., 2019. A Survey of Mobile Laser Scanning Applications and Key Techniques over Urban Areas. Remote Sensing, 11(13), 1540. doi.org/10.3390/rs11131540.

Wu, C.-T., Hsiao, C.-Y., Chen, C.-S., 2013. Improvement of LiDAR data accuracy using 12 parameter affine transformation. Journal of Chinese Soil and Water Conservation, 44(4), 293301.

Zhao, Y., 2011. GPS/IMU integrated system for land vehicle navigation based on MEMS. KTH Royal Institute of Technology, 85.

SP 47.13330.2016 «Engineering survey for construction. Basic principles», 2016, Moscow, TSNIIGAiK (in Russian).

Hutton, J., Roy, E. The Applanix SmartBase software for improved robustness, accuracy, and productivity of mobile mapping and positioning https://www.applanix.com/pdf/applanix\%20smartbase.pdf, (12 January 2020).

Scherzinger, B., Hutton, J. Applanix In-Fusion technology explained https://www.applanix.com/pdf/Applanix_INFusion.pdf (12 January 2020). 